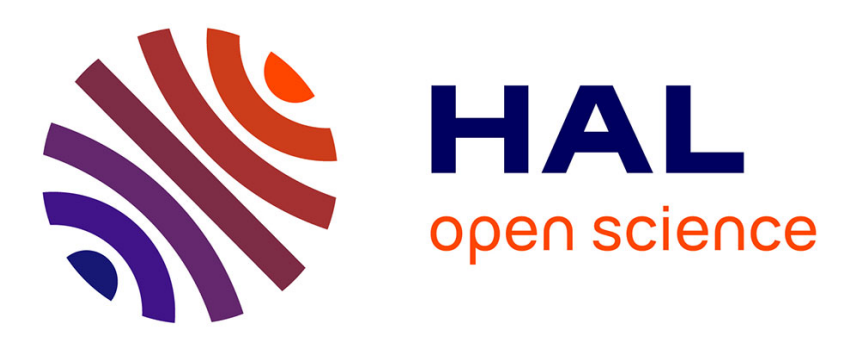

\title{
Necrosis of HepG2 cancer cells induced by the vibration of magnetic particles
}

Biran Wang, Céline Bienvenu, Juan Mendez-Garza, Pascal Lançon, Alexandra Madeira, Pierre Vierling, Christophe Di Giorgio, Georges Bossis

\section{- To cite this version:}

Biran Wang, Céline Bienvenu, Juan Mendez-Garza, Pascal Lançon, Alexandra Madeira, et al.. Necrosis of HepG2 cancer cells induced by the vibration of magnetic particles. Journal of Magnetism and Magnetic Materials, 2013, 344, pp.193-201. 10.1016/j.jmmm.2013.05.043 . hal-00878760

\section{HAL Id: hal-00878760 https://hal.science/hal-00878760}

Submitted on 30 Oct 2013

HAL is a multi-disciplinary open access archive for the deposit and dissemination of scientific research documents, whether they are published or not. The documents may come from teaching and research institutions in France or abroad, or from public or private research centers.
L'archive ouverte pluridisciplinaire HAL, est destinée au dépôt et à la diffusion de documents scientifiques de niveau recherche, publiés ou non, émanant des établissements d'enseignement et de recherche français ou étrangers, des laboratoires publics ou privés. 


\title{
Necrosis of HepG2 cancer cells induced by the vibration of magnetic particles
}

\author{
Biran Wang ${ }^{\mathrm{ab}}$, Céline Bienvenu, Juan Mendez-Garza, Pascal Lançon, Alexandra Madeira, Pierre \\ Vierling, Christophe Di Giorgio ${ }^{b^{*}}$, and Georges Bossis ${ }^{a^{*}}$ \\ ${ }^{a}$ Laboratoire de Physique de la Matière Condensée (LPMC), CNRS UMR 7336, Université de Nice-Sophia \\ Antipolis, Parc Valrose 06108 Nice, France \\ ${ }^{b}$ Institut de Chimie de Nice, UMR 7272, Université de Nice Sophia Antipolis, CNRS, 28, Avenue de Valrose, F- \\ 06100 Nice, France
}

\begin{abstract}
Experiments of magnetolysis, i.e. destruction of cells induced with magnetic particles (MPs) submitted to the application of a magnetic field, were conducted onto HepG2 cancer cells. We herein demonstrate the usefulness of combining anisotropic MPs with an alternative magnetic field in magnetolysis. Thus, the application of an alternative magnetic field of low frequency (a few Hertz) in the presence of anisotropic, submicronic particles allowed the destruction of cancer cells "in vitro". We also show that a constant magnetic field is far less efficient than an oscillating one. Moreover, we demonstrate that, at equal particle volume, it is much more efficient to utilize spindle like shape particles rather than spherical ones. In order to get deeper insight into the mechanism of magnetolysis experiments, we performed a study by AFM, which strongly supports that the magnetic field induces the formation of clusters of particles becoming then large enough to damage the cell membranes.
\end{abstract}

KEYWORDS: Cancer cells, Magnetic nanoparticles, magnetolysis

\section{* Correspondence:}

Laboratoire de Physique de la Matière Condensée (LPMC), CNRS UMR 7336, Université de Nice-Sophia Antipolis, Parc Valrose 06108 Nice, France Tel : +33 (0) 492076 538, Fax: +33 (0) 4920765336

bossis@unice.fr (G. Bossis),

Institut de Chimie de Nice, UMR 7272, Université de Nice Sophia Antipolis, CNRS, 28, Avenue de Valrose, F06100 Nice, France Tel : +33 (0)4 920765 08, Fax: +33 (0)4 92076151 christophe.di-giorgio@unice.fr (C. Di Giorgio) 


\section{INTRODUCTION}

Magnetic particles (MPs) are extensively used in biological assays, mainly due to the possibility to separate them from a culture medium by using a simple magnet. If their surface is functionalized to capture a given molecule, it allows to detect this molecule and to concentrate it easily [1]. For such applications, the size of the particles is around $1 \mu \mathrm{m}$ in order to generate a high enough magnetic moment - this being proportional to the volume of the particles- and, therefore, to obtain optimum magnetic separation. MPs are also used as platforms for numerous biomedical applications including diagnostics by magnetic resonance imaging(MRI) [2], magnetically targeted drug delivery and/or cancer therapy by hyperthermia [3]. For these last applications, the particles are heated by applying an alternative magnetic field and the increase of heat contributes to destroy tumor cells [4] or to expel the cargo drug molecules [5]. The size of the magnetic nanoparticles, which are used for hyperthermia is quite small (about $10 \mathrm{~nm}$ ) allowing their magnetic moment to fluctuate with a relaxation time of $10^{-5}$ to $10^{-6} \mathrm{~S}$ order and thus to present an optimum frequency, high enough for energy dissipation in an alternative field. However, the force, which can be induced by the gradient of an external magnetic field, is very low and is not sufficient to retain the particles in the vicinity of the tumor [6]. On the other hand, such small nanoparticles are quite easily taken up by cells through a clathrin-mediated endocytosis pathway (the limiting size of this process is around $200 \mathrm{~nm}$ ) [7]. In some cases, their internalization can strongly reduce the proliferation of cancer cells [8]. Particles in the 300-600 nm range can also be used for the embolization of tumor vasculature to necrotize tumor tissue [9].

Concerning cell lysis and tumor treatment, most of the research with MPs is focused on hyperthermia techniques with high frequency alternative magnetic field. However a few recent works have shown that tumor cells can be destroyed, both in vitro and in vivo, by the application of a low frequency magnetic field on micronic or submicronic magnetic particles.. For instance, the use of micronic iron particles injected in breast tumors of mice, when submitted to a strong permanent magnetic field (0.4T), resulted in tumor destruction [10]. Nevertheless this result was obtained with a very concentrated suspension ( $60 \%$ in weight) injected directly into the tumor. The other papers addressed the in vitro study of cancer cells with different kinds of field-responsive particles used at much lower volume fractions. In one of these reports, magnetic disks of $1 \mu \mathrm{m}$ diameter and 60 $\mathrm{nm}$ thickness, when actuated by a magnetic field of $10-20 \mathrm{~Hz}$ frequency and about $90 \mathrm{Oe}$ amplitude during 10 min, caused cell death [11]. As the estimated amplitude of penetration of the particles inside the membrane due to the magnetic torque was quite low, the authors concluded that cell death was not the result of cell membrane damage but, instead, of the triggering of intracellular pathways activating programmed cell death (apoptosis), caused by the alternative low frequency motion. In another study, smaller organic particles with a diameter around $200 \mathrm{~nm}$, containing magnetic nanoparticles of $5 \mathrm{~nm}$ diameter embedded into the polystyrene matrix were used [12]. Due to phase separation during the embedding step, the magnetic nanoparticles were aggregated only on one side (pole) of the resulting organic particles. Here too, when submitted to a rotating field at a frequency of $50 \mathrm{rpm}$ and after $15 \mathrm{~min}$ exposure to the spinning magnetic field, the majority of the tumor cells were killed as evidenced by trypan blue staining. The rapidity of the staining by the trypan blue indicated further that cell destruction was related to membrane damage and not to apoptosis.

Very recently, multiwall carbon nanotubes containing iron impurities making them paramagnetic when placed into a rotating field of amplitude above $40 \mathrm{mT}$ during $20 \mathrm{~min}$, were reported to induce a significant decrease of cell viability [13].

All these studies demonstrated a magnetolysis effect but only for some special experimental parameters, which are related to the type of magnetic particles and the conditions of application of the magnetic field. Nevertheless the explanation of the phenomenon remained qualitative and somewhat contradictory between direct damage caused to the membrane of the cells and apoptosis indirectly triggered by the application of a mechanical solicitation. The goals of the work reported here were (i) to confirm that, using anisotropic MPs, moderate magnetic fields can be sufficient to destroy cancer cells at low frequency, and (ii) to bring new insight in the in vitro magnetolysis process of cells in culture. Aiming at these goals, we have used two different kinds of MPs (spindle or spherical) in conjunction with a well controlled magnetic field gradient (alternative or constant) allowing to calculate precisely the applied force. The resulting penetration into the cell by the different types of MPs (spindle or spherical morphology, size) was derived from the knowledge of the mechanical response function of the cell obtained from experiments made by atomic force microscopy (AFM). This model was used to explain how the MPs can mechanically cause cell damage. Furthermore, direct indentation of the cells by an AFM tip was used to confirm our hypothesis on the intensity of forces necessary to damage the cells, and also to determine the best conditions to obtain magnetolysis with MPs. 


\section{MATERIALS AND METHODS}

\subsection{Cell cultures}

HepG2 cells (liver hepatocellular carcinoma) were grown in Dulbelcco modified Eagle culture medium (DMEM; Gibco-BRL) containing 10\% v/v fetal calf serum (FCS; Sigma), glucose $(4.5 \mathrm{~g} / \mathrm{L})$, glutamine $(2 \mathrm{mM})$, penicillin (100 units $/ \mathrm{mL}$ ), $100 \mu \mathrm{g} \mathrm{mL} \mathrm{m}^{-1}$ streptomycin in a wet $\left(37^{\circ} \mathrm{C}\right.$ ) and $5 \% \mathrm{CO}_{2} / 95 \%$ air atmosphere.

\subsection{Mortality assays by trypan blue staining}

Twenty-four hours before analysis, HepG2 cells were seeded at confluence, i.e. density of $610^{5}$ cells per dish (BD Falcon ${ }^{\mathrm{TM}} 35 \mathrm{~mm}$ Easy-Grip ${ }^{\mathrm{TM}}$ Cell Culture Dish). The culture medium was then removed and replaced by $2 \mathrm{~mL}$ of a fresh DMEM supplemented with 10\% FCS. A suspension of MPs was made by mixing MPs (spherical or acicular) with the cell culture medium at a mass ratio of 1\%. Each MPs suspension was then added to each Petri dish containing the cells with final mass ratio of particles between $0.1 \%$ and $0.01 \%$ in $1 \mathrm{ml}$ of total culture medium, and then kept at $37^{\circ} \mathrm{C}$ in the incubator for 4 hours. Each Petri dish was then subjected to a magnetic field (constant or alternative) during $20 \mathrm{~min}$ or $60 \mathrm{~min}$. Blanks were made with dishes containing the cells and the MPs that were not placed into the magnet. All dishes containing the cells as well as the MPs suspension were kept at $37^{\circ} \mathrm{C}$ in the incubator for an additional time of $30 \mathrm{~min}$. Each culture medium was then removed apart and cells were rinsed 3 times with PBS $(1 \mathrm{~mL}) .500 \mu 1$ of DMEM were added in each of the Petri dishes, and $100 \mu \mathrm{L}$ of $0.4 \%$ trypan blue staining solution was mixed by shaking the Petri dish. Before counting the dead cells, $5 \mathrm{~min}$ of stand time were allowed at room temperature. The results of mortality were obtained by taking several pictures under a microscope, each of them containing approximately 50-100 cells and then counting the fraction of dead cells on each picture. This counting is realized only on the cells, which are still adherents to the dish bottom.

\subsection{Magnetic particles}

Two types of particles were used in this study: homemade spindle-type Fe@Silica particles and commercial spherical ferromagnetic particles. Both types received a surface modification to provide passivation and full dispersion into biological media.

\subsubsection{Spindle-type Fe@Silica particles}

The spindle-type magnetic particles have been synthesized in the laboratory using a 3-step process. First nonagglomerated spindle-type hematite were synthesized according to literature procedure [14]. Then iron oxide particles were transformed into iron by reduction of the ferrous oxide in a hydrogen flow at $400^{\circ} \mathrm{C}$ during $4 \mathrm{~h}$. The particles are quite well monodisperse with an average length of $580 \mathrm{~nm}$ and a small axis of $80 \mathrm{~nm}$ (cf. upper Error! Not a valid bookmark self-reference.: The SEM image of spindle like iron particles; upper picture: dimensions of a single particle; lower picture: particles covered with silica

). At last, silica was deposited at their surface, using tetraethoxysilane (TEOS). Basically $1 \mathrm{~g}$ of particles was dispersed into ethanol containing $5 \%(\mathrm{v} / \mathrm{v})$ of water for the hydrolysis and the $\mathrm{pH}$ was set to 10 with ammonia. A solution containing $3 \mathrm{ml}$ of TEOS in $10 \mathrm{ml}$ of ethanol was then added progressively, with a syringe at the velocity of $100 \mu \mathrm{L} / \mathrm{min}$, to the iron suspension under agitation. After agitation during $12 \mathrm{~h}$; the particles were centrifugated and washed with ethanol three times, then dried and kept under nitrogen atmosphere. Success of surface treatment was checked by SEM microscopy with a JEOL 6700F SEM, a cold field-emission gun Scanning electron microscope (FEG-SEM) operating at 0.5 to $30 \mathrm{kV}$ with an ultimate resolution of $1.0 \mathrm{~nm}$, and a magnification range of 10x to 700,000x. Silica coverage is clearly seen on the lower picture of Error! Not a valid bookmark self-reference.: The SEM image of spindle like iron particles; upper picture: dimensions of a single particle; lower picture: particles covered with silica

\footnotetext{
. The magnetization versus field is shown in Error! Not a valid bookmark self-reference.: The magnetization curve of Fe (black) and Fe@Silica (red) spindle like particles

, both for Fe and Fe@Silica MPs. The difference between the two curves is related to the thickness of the silica layer. The magnetization saturation of Fe@Silica MPs was slightly decreased by the presence of the silica layer from $156 \mathrm{uem} / \mathrm{g}$ to $137 \mathrm{uem} / \mathrm{g}$. The ratio of the saturation magnetizations corresponds to a mass of silica, which is $14 \%$ of the initial mass of the iron particle. On the other hand, the average susceptibility, $\chi$, for a field of 1500 Oe, which corresponds to the end of the hysteresis loop, is equal to 5.
} 


\subsubsection{Spherical Fe@Silica particles}

Beside these elongated particles we have also used commercial carbonyl iron powders (BASF, grade HQ, Germany), consisting of spherical ferromagnetic particles, which are currently used to prepare magnetorheological fluids. Their surface has been covered with aminopropyltriethoxysilane (APTES) in order to avoid oxidation. The iron powder was first heated in trichloroethylene under reflux during $5 \mathrm{~h}$ in order to remove impurities and oxide layer. The APTES was hydrolyzed during $15 \mathrm{~min}$ in an acidic solution of ethanol containing $5 \%$ in volume of water brought to $\mathrm{pH} 5$ with acetic acid. Then the iron powder was added to this solution containing silanol groups and let under agitation during $12 \mathrm{~h}$.

The diameters of the resulting particles are from several hundred of nm to a few $\mu \mathrm{m}$, as found by SEM (Error! Reference source not found.). Their magnetization curve shows no hysteresis at all and a higher saturation magnetization than spindle like particles. Nevertheless the field, $\mathrm{H}$, inside a spherical particle is decreased due to its demagnetizing field and $\mathrm{H}$ is equal to $3 H_{0} /(3+\chi)$ [15] instead of $H_{0}$ for a needle aligned on the field direction. Thus the magnetization inside one spherical particle $(M=\chi H)$ is equal to $3 \mathrm{H}_{0}$ if $\chi>>1$, which is the case for iron; so in the following we shall take $\mathrm{M}=3 \mathrm{H}_{0}$ for the magnetization of spherical iron particles.

\subsection{Experimental magnetolysis setup}

The experimental setup consisted of a non-magnetic plate tightly fixed above a modal exciter (Brüel \& Kjær type 4824, Nærum, Denmark) by 3 rods, as shown in Error! Not a valid bookmark self-reference.: Experimental magnetolysis setup

, the $35 \mathrm{~mm}$ Petri dish (BD, Franklin Lakes, NJ) containing the cancer cells was fixed inside a cylinder, which is screwed inside a hole at the center of the plate and can be moved vertically. A $58 \mathrm{~mm}$ diameter neodymium magnet was stuck on the top of the exciter, right under the plate, coaxially.

The exciter is controlled by a sinusoidal signal-through a dedicated amplifier. The magnet can easily vibrate at full amplitude from 0 to $10 \mathrm{~Hz}$ and the amplitude of vibration was adjusted in such a way that the magnet almost touches the dish bottom at its upper point.

The determination of the magnetic field generated on the dish bottom was made as follow. First, we measured the magnetic field generated by the neodymium magnet in function of the distance $x$. These data can be quite well fitted by a linear function, so that we can approximate the magnetic field gradient $\nabla H_{x}$ as:

$$
\nabla H_{x}=\frac{H_{\max }-H_{\min }}{L}=\frac{\Delta H}{L}
$$

Since the vibration is sinusoidal in the $x$ direction, the motion of the magnet as a function of time is:

$$
x=x_{0}+\frac{L}{2}(1+\sin \omega t)
$$

where $L$ is the amplitude of the sinusoidal motion, and $x_{0}$ is the lower position of the magnet, and $\omega$ is the angular frequency.

So the magnetic field created by the magnet is:

$$
H=H_{\min }+\frac{\Delta H}{2}(1+\sin \omega t)
$$

where $H_{\min }$ is the magnetic field in the Petri dish when the magnet is at $x_{0}$, and $H_{\max }$ is the magnetic field in the Petri dish when the magnet is at $x_{0}+L$.

\subsubsection{Applied magnetic force}

The applied magnetic force on a particle is given by: 


$$
F_{H}(t)=\mu_{0} m \nabla H_{0}=\mu_{0} \chi V_{p} H_{0} \nabla H_{0}
$$

where $\chi$ is the effective magnetic susceptibility of the particle in the applied field, $V_{p}$ is the volume of one particle. From Eqs. (1), (3) and (4), we have:

$$
F_{H}(t)=\mu_{0} \chi V_{p} \frac{\Delta H}{L}\left[H_{\text {min }}+\frac{\Delta H}{2}(1+\sin \omega t)\right]
$$

or in a more condensed way:

$$
F_{H}(t)=C_{0}+C_{1} \sin \omega t
$$

where

$$
C_{0}=\mu_{0} \chi V_{p} \frac{\Delta H}{L}\left[H_{\min }+\frac{\Delta H}{2}\right] \text { and } C_{1}=\mu_{0} \chi V_{p} \frac{\Delta H^{2}}{2 L}
$$

the effective magnetic susceptibility being $\chi=3$ for iron spheres and $\chi=5$ for spindle like iron particles, as explained in section Materials and methods.

\subsection{AFM experiments}

The AFM model 5100 from Agilent was used in the force spectroscopy mode to obtain the mechanical properties of the cells. Two kinds of AFM tips, i.e. a spherical one of diameter $5 \mu \mathrm{m}$ (Novascan Technologies, Ames, IA) and a conical one (Nanoscience Instruments, Inc. Phoenix, AZ) were used. This last tip has a conical angle $\beta$ of $30^{\circ}$, which is close to that of the spindle particles $\left(\beta=29^{\circ}\right)$. The protocol used to determine the mechanical properties of the cell is described elsewhere [16]. For periodic indentation of the cells a maximum deflection of the cantilever is defined, corresponding to a given applied force and the tip was continuously moving at a defined frequency between the maximum deflection and a minimum one in the liquid above the cell.

\section{RESULTS AND DISCUSSION}

\subsection{Mortality assay under magnetic field}

The mortality of HepG2 cells has been measured by the trypan blue assay. The reactivity of trypan blue is based on the fact that the chromophore is negatively charged and enters into the cell only when the membrane is damaged [17].

Each Petri dish, prepared as mentioned in section Materials and Methods and containing medium, adherent HepG2 cells with spherical or acicular MPs, was placed above the vibrating magnet during a given period of time (20, 40 or $60 \mathrm{~min})$. During the same time, a reference dish with the same content of materials, i.e. medium, cells and MPs but not subjected to the magnetic field was used as a blank. At the end of this experiment, all Petri dishes were put in the incubator for additional $30 \mathrm{~min}$. Then, the different dishes were treated as mentioned in section Materials and Methods and stained for the trypan blue assay. The results of the mortality (expressed as a mortality ratio, i.e. number of died cells divided by the total number of cells) are shown in Error! Not a valid bookmark self-reference.: Mortality ratio for the spindle-type particles versus frequency of the magnetic field. The data at $0 \mathrm{~Hz}$ are without field, except the blue square, which corresponds to a permanent field $\mathrm{H}=160 \mathrm{kA} / \mathrm{m}$

and Error! Not a valid bookmark self-reference.: Mortality ratio for the spherical particles versus frequency of the magnetic field. The data at $0 \mathrm{~Hz}$ are without field, except the blue square, which correspond to a permanent field $\mathrm{H}=160 \mathrm{kA} / \mathrm{m}$

for spindle like particles and spherical particles, respectively. It should be noticed that the counting was realized only on the cells which were still adherent to the dish bottom; consequently, the mortality ratio could be underestimated. However, the microscopy pictures show a density of cells that seems identical before and after the treatment, indicating that only a few cells came out of the support. The results presented in Error! Not a valid bookmark self-reference.: Mortality ratio for the spindle-type particles versus frequency of the 
magnetic field. The data at $0 \mathrm{~Hz}$ are without field, except the blue square, which corresponds to a permanent field $\mathrm{H}=160 \mathrm{kA} / \mathrm{m}$

are given for different initial concentrations of particles and for 20,40 or $60 \mathrm{~min}$ of exposure to the field. The concentration is a weight ratio and the total volume of feeding liquid above the layer of cells is $1 \mathrm{~mL}$. The data at zero frequency represent both the results obtained with the blanks (not submitted to magnetic field) and those, in blue and shifted to the left of zero frequency, performed with a constant field, corresponding to $H_{\max }$.

As shown in Error! Not a valid bookmark self-reference.: Mortality ratio for the spindle-type particles versus frequency of the magnetic field. The data at $0 \mathrm{~Hz}$ are without field, except the blue square, which corresponds to a permanent field $\mathrm{H}=160 \mathrm{kA} / \mathrm{m}$

and Error! Not a valid bookmark self-reference.: Mortality ratio for the spherical particles versus frequency of the magnetic field. The data at $0 \mathrm{~Hz}$ are without field, except the blue square, which correspond to a permanent field $\mathrm{H}=160 \mathrm{kA} / \mathrm{m}$

, there is a significant increase of cell mortality when the particles are submitted to an oscillating magnetic field with a clear relationship between mortality and the utilized mass fraction of particles or the time of exposure. Besides, cell mortality shows a small tendency to increase with the applied frequency between 2 and $10 \mathrm{~Hz}$. At last, we can see that there is an increase of mortality ratio when the time of exposure was increased from 20 to 40 or $60 \mathrm{~min}$.

In order to understand the process involved, and, more precisely, to determine whether the death of the cells is due to the pressure exerted on their surface by the magnetic particles, or to the vertical oscillating motion of the particles, we assayed the mortality by running dishes with a constant magnetic field whose value is equal to the maximum of the oscillating field. As shown in Error! Not a valid bookmark self-reference.: Mortality ratio for the spindle-type particles versus frequency of the magnetic field. The data at $0 \mathrm{~Hz}$ are without field, except the blue square, which corresponds to a permanent field $\mathrm{H}=160 \mathrm{kA} / \mathrm{m}$

and Error! Not a valid bookmark self-reference.: Mortality ratio for the spherical particles versus frequency of the magnetic field. The data at $0 \mathrm{~Hz}$ are without field, except the blue square, which correspond to a permanent field $\mathrm{H}=160 \mathrm{kA} / \mathrm{m}$

(blue dot), the mortality ratio remains practically at the same level than in the absence of magnetic field, though the field was at its maximum value during the duration of the experiment, contrary to the vibrating case.

As the mortality takes place quickly after the application of the magnetic field, mechanisms like apoptosis, which requires a few hours for its activation, are excluded, and it is likely that mechanical damage of the membrane is responsible for the increase in cell mortality..

\subsection{Prediction of the indentation of cells by magnetic particles}

In order to get a deeper insight into the magnetolysis mechanism, which leads to cell death, it was necessary to know more precisely about the penetration or indentation depth of the particles inside the cell when applying a given magnetic force. Aiming at this goal, we examined the indentation of cells as supported by previous AFM characterization of the $\mathrm{HepG}_{2}$ cell rheology [16]. A Zener model (represented by a spring $G_{1}$ and a damper $\eta_{1}$ in series, connected with a second spring a spring, $G_{0}$, in parallel, cf. appendix), with shear moduli $G_{0}$ of $210 \mathrm{~Pa}$ and $G_{1}$ of $118 \mathrm{~Pa}$, and a relaxation time $\tau_{1}=\eta_{1} / G_{1}$ of $5.6 \mathrm{~s}$, was shown to correctly represent the response function of these cells to a sudden application of a force.

The indentation depth, $\delta$, of a particle inside an elastic medium can be modelled by the time dependent generalization of the Hertz model. For the sinusoidal force given by Eq.(6), the analytical solution for the $\delta(t)$ indentation is given by $H(t)=\delta^{3 / 2}$ for a spherical indenter and $H(t)=\delta^{2}$ for a conical one (cf. Eqs.Error! Reference source not found. and Error! Reference source not found. in appendix) with

$H(t)=\frac{1}{C} \frac{C_{1}}{G_{0}}\left[\sin \omega t-\frac{G_{1}}{G_{1}+G_{0}} \frac{\omega \tau}{1+\omega^{2} \tau^{2}}\left(\cos \omega t+\omega \tau \sin \omega t-e^{-t / \tau}\right)\right]+\frac{C_{0}}{C} J(t)$

where the constant $C$ is depending on the shape of the indenter (see appendix). For $t>>$, which is the case in our experiments, the exponential term disappears in Eq.(7) and it remains an oscillating part $H_{\text {osc }}(\mathrm{t})$, and a 
constant indentation $H_{p}=\frac{1}{C} \frac{C_{0}}{G_{0}}$ related to the constant part of the applied force (Eq.(6)), since $J(t>>\tau)=1 / G_{0}$ (cf. appendix). The amplitude in microns of the oscillating part of the indentation: $A=\delta_{\max }-\delta_{\min }$ is plotted in Error! Not a valid bookmark self-reference.: Amplitude of the oscillation versus the reduced frequency Wт. Upper and lower curves correspond to spherical and spindle like particles, respectively.

for the two kinds of particles. It can be seen that the amplitude decreases with the frequency and is approximately ten-fold larger for the spherical particle than for the spindle one. Actually this lower indentation of the spindle particle is due to the difference in volume between the two particles, which for the spherical particle is of $4.2 \mu \mathrm{m}^{3}$ and for the spindle-type particle of $0.002 \mu \mathrm{m}^{3}$, hence 2000 -fold lower. This indicates that, for particles of equal volume, it is much more efficient to obtain a mechanical perforation of the membrane with spindle particles rather than with spherical ones.

As can be seen in Error! Not a valid bookmark self-reference.: Amplitude of the oscillation versus the reduced frequency respectively.

, for the spherical particle, the amplitude of indentation decreases from $20 \mathrm{~nm}$ when $\omega \tau \ll$ to $7 \mathrm{~nm}$ for $\omega \tau \gg$. For the spindle particle, the amplitude decreases from $2 \mathrm{~nm}$ for $\omega \tau \ll$ to about $1.2 \mathrm{~nm}$ for $\omega \tau \gg$. The transition frequency corresponding to $\omega \tau=1$ is $v \approx 0.02 \mathrm{~Hz}$, indicating that with a few Hertz the "high frequency" regime is already attained.

In the experiments with the magnet at rest just under the Petri dish, the applied magnetic force is constant and equal to $C_{0}+C_{1}$ (cf. Eq. (6) ) and the maximum indentation will be:

$H_{\max }=\frac{1}{C} \frac{C_{0}+C_{1}}{G_{0}}$

Using $H=\delta^{3 / 2}$ for a sphere and $H=\delta^{2}$ for a cone together with the respective values of $C$ (cf. appendix), one obtains, $\delta_{\max }=71 \mathrm{~nm}$ for the sphere and $\delta_{\max }=9.6 \mathrm{~nm}$ for the cone.

In summary, the amplitude of the "oscillating" indentation should be around $1 \mathrm{~nm}$ for the spindle particles and 7 $\mathrm{nm}$ for the spherical ones, but the "static" indentation under the maximum permanent field is $9.6 \mathrm{~nm}$ and $71 \mathrm{~nm}$ for the spindle and spherical particle, respectively. This theoretical analysis indicates further that the indentation generated by a static magnetic field is much larger than that obtained with an oscillating one of same amplitude and that the indentation depth remains quite small and in any case lower than $100 \mathrm{~nm}$.

On the other hand, we have found experimentally (see above) that a static indentation has no noticeable effect on the cell viability and that an oscillation was needed to damage the cells. This likely indicates that the dynamics of indentation plays the major role and that, like in hyperthermia, it could be the dissipation of mechanical energy in heat, which provokes cell death, since this dissipation increases with the frequency. The dissipated power per particle is given by:

$$
P\left(t_{0}\right)=\frac{1}{T} \int_{t_{0}}^{t_{0}+T} F_{H}(t) i
$$

where $T$ is at least one period and $t_{0}>>\tau$, in order to get the equilibrium value. The dissipated power versus frequency reaches a plateau at frequencies above $v=1 / \tau=0$. However, its value is very low $\left(4 \times 10^{-20}\right.$ Watt per particle). As only an average of a few tens of particles is interacting with a single cell, it is unlikely that the dissipated power results into any noticeable increase of temperature and, consequently, into cell death by hyperthermia.

\subsection{Mechanical AFM indentation to simulate the magnetic indentation}

We have found in the previous section that the amplitude of the oscillating indentation due to an isolated magnetic particle was not larger than a few $\mathrm{nm}$ with an associated magnetic force in the $\mathrm{pN}$ range. Therefore, it is very doubtful that the observed cell death can be related to such a low indentation. 
The same kind of mechanical indentation can be applied on cells by use of an AFM tip. To check whether this force induces cell death, we then used an AFM tip either with a conical or a spherical shape in order to apply on a given cell an oscillating indentation of known amplitude. The conical probe had approximately the same conical angle and size as a spindle type particle. Applying a force of a few $\mathrm{pN}$, the probe did not cause any damage to the cells. It is only when increasing the force in the $\mathrm{nN}$ range that membrane damage and then cell death could be obtained, as illustrated in the sequence of Error! Not a valid bookmark self-reference.: Mortality test of a HepG 2 cell (red circle) by indentation with a conical AFM tip. (1) before treatment; (2) immediatly after indentation during $20 \mathrm{~min}$; (3) $15 \mathrm{~min}$ and (4) $1 \mathrm{~h}$ after indentation.. The dead cell (yellow circle) is a landmark

. At the beginning of the experiment (Error! Not a valid bookmark self-reference.: Mortality test of a $\mathrm{HepG}_{2}$ cell (red circle) by indentation with a conical AFM tip. (1) before treatment; (2) immediatly after indentation during $20 \mathrm{~min}$; (3) $15 \mathrm{~min}$ and (4) $1 \mathrm{~h}$ after indentation.. The dead cell (yellow circle) is a landmark

-1), we can see two cells, one is intact and the other is already dead and strongly coloured by the trypan blue, it serves as a position marker. Then the intact cell was periodically indented by the conical probe during $20 \mathrm{~min}$, with a force of $1 \mathrm{nN}$, corresponding to an indentation depth of $400 \mathrm{~nm}$ and a frequency of $5 \mathrm{~Hz}$ (Error! Not a valid bookmark self-reference.: Mortality test of a $\mathrm{HepG}_{2}$ cell (red circle) by indentation with a conical AFM tip. (1) before treatment; (2) immediatly after indentation during $20 \mathrm{~min}$; (3) $15 \mathrm{~min}$ and (4) $1 \mathrm{~h}$ after indentation.. The dead cell (yellow circle) is a landmark

-2). Fifteen minutes after the indentation period, there are some blebs blown up (Error! Not a valid bookmark self-reference.: Mortality test of a $\mathrm{HepG}_{2}$ cell (red circle) by indentation with a conical AFM tip. (1) before treatment; (2) immediatly after indentation during $20 \mathrm{~min}$; (3) $15 \mathrm{~min}$ and (4) $1 \mathrm{~h}$ after indentation.. The dead cell (yellow circle) is a landmark

-3), then those blebs are expelled 45 min after the indentation and the cell loses its integrity and is stained by the trypan blue dye, indicating cell death (Error! Not a valid bookmark self-reference.: Mortality test of a $\mathrm{HepG}_{2}$ cell (red circle) by indentation with a conical AFM tip. (1) before treatment; (2) immediatly after indentation during $20 \mathrm{~min}$; (3) $15 \mathrm{~min}$ and (4) $1 \mathrm{~h}$ after indentation.. The dead cell (yellow circle) is a landmark

$-4)$.

To mimic the use of spherical magnetic particles, we also performed the same experiment by using a spherical tip of $2.5 \mu \mathrm{m}$ radius instead of the conical one. Four amplitudes of oscillation, i.e. 100, 200, 300 and $400 \mathrm{~nm}$, were used.. The red and yellow circles in Error! Not a valid bookmark self-reference.: Mortality test of a $\mathrm{HepG}_{2}$ cell (red circle) by indentation with a spherical tip. left and right : before and after treatment for $20 \mathrm{~min}$ and with a frequency of $5 \mathrm{~Hz}$, respectively. Red and yellow circle: cell treated with an amplitude of 400 and $300 \mathrm{~nm}$, respectively. Red and yellow circle: cell treated with an amplitude of 400 and $300 \mathrm{~nm}$, respectively.

represent cells, which were submitted to two imposed amplitudes (400 and $300 \mathrm{~nm}$ respectively) for 20 min and with a frequency of $5 \mathrm{~Hz}$. The impact of the amplitude is clearly evidenced in Error! Not a valid bookmark self-reference.: Mortality test of a $\mathrm{HepG}_{2}$ cell (red circle) by indentation with a spherical tip. left and right : before and after treatment for $20 \mathrm{~min}$ and with a frequency of $5 \mathrm{~Hz}$, respectively. Red and yellow circle: cell treated with an amplitude of 400 and $300 \mathrm{~nm}$, respectively. Red and yellow circle: cell treated with an amplitude of 400 and $300 \mathrm{~nm}$, respectively.

where the cell stressed with an indentation amplitude of $400 \mathrm{~nm}$ becomes coloured by the trypan blue (red circle) whereas the other one stressed with the lower amplitude of $300 \mathrm{~nm}$ (or below, data not shown) remains intact (yellow circle).

It should be noticed that the associated oscillating force corresponding to the indentation amplitude of $400 \mathrm{~nm}$ is of $1.8 \mathrm{nN}$. This is coherent with the forces needed for the magnetolysis of red blood cells as reported by Hategan and al., which are in the $\mathrm{nN}$ range [18]. Then, in our magnetolysis experiments, it seems most unlikely that the magnetic force on a single particle, which is smaller by at least two orders of magnitude, is responsible for cell death. Thus, in the case of our experiments, magnetolysis can be related to the formation of clusters of particles on the cell surface, which are indeed observed when the magnetic field is applied, as illustrated in Error! Not a valid bookmark self-reference.: Photo of spherical iron particles above $\mathrm{HepG}_{2}$ cells before (upper part) 
. These clusters of irregular shape are formed as a result of particle's self-attraction. When these clusters become large enough, their magnetic moment (which is increasing proportionally with their volume) can thus become sufficient for allowing the clusters to damage the cell membrane. Furthermore these elongated clusters should align in the direction of the field, hence perpendicularly to the surface of the cells. Consequently, the curvature radius of the indentation tip remains of the same order of magnitude as the one of a single particle. For instance, if a cluster contains 100 particles and as the indentation for an elongated cluster increases with the square root of the force (cuff Eq. Error! Reference source not found.), which is itself proportional to the number of particles, one obtains an indentation depth corresponding to a force of one order of magnitude larger than for isolated particles. As shown with AFM tips, this is large enough to mechanically damage the cells.

The formation at the cell surface of clusters of paramagnetic carbon nanotubes when submitted to a rotating field has also been reported very recently [13]. Here too the application of the field was associated with a net decrease of cell viability. It is therefore the clustering of magnetic particles under the applied field, which can be responsible for the destruction of the cells. Nevertheless, it remains a mystery about the need of an oscillating force, since a static one of comparable amplitude has no influence on cell viability. It could be however related to a characteristic time of membrane healing after perforation. The indentation of particles is likely inducing in its vicinity a size increase of the fluctuating channels in the membrane. The resealing time of pores in cells is extremely variable but can be of the order of seconds in the presence of an hydraulic stress [19], and long enough in the case of an oscillating stress to lead to cell death. We intend in a further study to use conductivity measurements to verify if this hypothesis is supported by a correlation between the frequencies of the applied field and pore formation.

\section{CONCLUSIONS}

We have found that, as already observed in similar situations, it is possible to damage cancer cells with magnetic particles of sizes in the range of $100 \mathrm{~nm}$ to a few microns by exposing them to an alternative magnetic field. Besides, we show that a static magnetic force was much less efficient than an oscillating one. By using a device, which imposes a well defined magnetic force, and with the help of AFM to characterize the mechanical properties of HepG2 cells, we demonstrated that the indentation caused by the magnetic force is only of the order of a few nm. Such a low indentation, imposed through an AFM tip, is unable to provoke cell damage. Indeed, at least a few hundred $\mathrm{nm}$ of indentation is needed to trigger cell death, as observed with the trypan blue staining assay. Our observation of a clustering of the particles under magnetic field, suggests strongly that it is the formation of magnetic particle aggregates, which considerably increases the magnetic force and their pressure onto the cells, and, consequently, causes membrane damage and ultimately cell death. The results obtained with submicronic spindle like particles are promising, since with particles of $10^{-3} \mu \mathrm{m}^{3}$ volume order, which can indeed circulate in blood capillaries without causing embolism, it was possible to destroy cells with a moderate field, such as those easily obtained in MRI scanners.

Concerning the need of an alternative field rather than a static one to obtain a clear cell mortality increase, a mechanism of delayed pore resealing could be at its origin. Further investigations coupling periodic indentation and conductivity measurements should help to verify this hypothesis. If this is the case, then a control of the applied magnetic force by magnetic particles could be a mean to trigger membrane permeabilization and intracellular drug delivery. Also, other events, such as apoptosis (in earlier and late stages) will be studied through flow cytometry experiments with the use of appropriate dyes. Finally, investigations to target selectively these anisotropic magnetic particles to the surface of cancer cells by using ligands that are specifically recognized by overexpressed receptors are currently in progress and will be reported soon.

\section{ACKNOWLEDGEMENTS}

The authors thank the Région Provence, Alpes, Côte d'Azur and the CNRS for their financial support of the project BIOMAG and for a doctoral fellowship to BW. We are also grateful to Mrs Girard for her help with Abaqus simulations. At last, authors would like to thank the "Centre Commun de Microscopie Appliquée" (S. Pagnotta and P. Gounon) of Nice university for their help with electronic microscopy experiments. 


\section{REFERENCES}

[1] J. Gao, H. Gu, B. Xu, Acc. Chem. Res 42 (2009) 1097.

[2] C. Lok, Nature 412 (2001) 372.

[3] S.F. Medeiros, A.M. Santos, H. Fessi, A. Elaissari, Int. J. Pharm. 403 (2011) 139.

[4] G. Beaune, M. Levy, S. Neveu, F. Gazeau, C. Wilhelm, C. Ménager, Soft Matter 7 (2011) 6248.

[5] O. Sandre, L. Moreaux, F. Brochard-Wyart, Proc. Natl. Acad. Sci. USA 96 (1999) 10591.

[6] A.S. Lübbe, C. Alexiou, C. Bergemann, J. Surg. Res. 95 (2001) 200.

[7] J. Rejman, V. Oberle, I.S. Zuhorn, D. Hoekstra, Biochem. J. 377 (2004) 159.

[8] I.W. Bauer, S.-P. Li, Y.-C. Han, L. Yuan, M.-Z. Yin, J. Mater. Sci. Mater. Med. 19 (2007) 1091.

[9] N.J. Darton, B. Hallmark, T. James, P. Agrawal, M.R. Mackley, N.K.H. Slater, J. Magn. Magn. Mater. 321 (2009) 1571.

[10] M.N. Bouchlaka, G.D. Sckisel, D. Wilkins, E. Maverakis, A.M. Monjazeb, M. Fung, L. Welniak, D. Redelman, A. Fuchs, C.A. Evrensel, W.J. Murphy, PLOS ONE 7 (2012) e48049.

[11] D.-H. Kim, E.A. Rozhkova, I.V. Ulasov, S.D. Bader, T. Rajh, M.S. Lesniak, V. Novosad, Nat. Mater. 9 (2010) 165

[12] S.-H. Hu, X. Gao, J. Am. Chem. Soc. 132 (2010) 7234.

[13] D. Liu, L. Wang, Z. Wang, A. Cuschieri, Nano Lett. 12 (2012) 5117.

[14] T. Ishikawa, E. Matijevic, Langmuir 4 (1988) 26.

[15] D.J. Griffiths, Introduction to electrodynamics, Pearson, San Francisco, 2008.

[16] B. Wang, P. Lançon, C. Bienvenu, P. Vierling, C. Di Giorgio, G. Bossis, Micron 44 (2013) 287.

[17] R.I. Freshney, Culture of animal cells : a manual of basic technique, Wiley-Liss, New York, N.Y., 2000.

[18] A. Hategan, R. Law, S. Kahn, D.E. Discher, Biophys. J. 85 (2003) 2746.

[19] J. Teissie, M. Golzio, M.P. Rols, Biochim. Biophys. Acta 1724 (2005) 270.

[20] E.K. Dimitriadis, F. Horkay, J. Maresca, B. Kachar, R.S. Chadwick, Biophys. J. 82 (2002) 2798.

[21] I.N. Sneddon, Int. J. Eng. Sci 3 (1965) 47.

[22] A.L. Weisenhorn, M. Khorsandi, S. Kasas, V. Gotzos, H.-J. Butt, Nanotechnology 4 (1993) 106.

\section{APPENDICE: THEORY FOR THE DYNAMIC INDENTATION OF A CELL}

The penetration, or indentation depth, $\delta$, of a particle inside an elastic medium can be modelled by the Hertz theory. For a spherical particle of radius R, the relation between the force $F$ and the penetration, $\delta$, is given by:

$$
F=\frac{4 \sqrt{R}}{3} \frac{E}{1-v^{2}} \delta^{\frac{3}{2}}
$$

where, $E$ is the Young modulus and $v$ the Poisson coefficient that we shall take equal to 0.5 , since the cell is usually considered as an incompressible medium [20]. For an acicular particle, the total indentation force is given by $[21,22]$ :

$F=\frac{2}{\pi} \frac{E}{1-v^{2}} \frac{\delta^{2}}{\tan \beta}$

where $\beta$ is the angle between the surface of the material and the surface of the cone; for the spindle Fe@Si particles that we described here, their extremity can be considered to be conical. Based on MEB image (cuff Fig. 1 ), $\beta=\pi / 2-\theta$ is equal to $75^{\circ}$. In this case, the indentation depth and the radius of the contact area, $a$, are further related by:

$\delta=\frac{\pi}{2} a \tan \beta$

The Eq.Error! Reference source not found. for a spherical contact and the Eq.(A-2) for a conical contact can then be written as:

$F=C G H$ or $H=\frac{1}{C} J F$ 
with $G=E / 3, C=4 \sqrt{R} / 1-v^{2}$ and $H=\delta^{3 / 2}$ in the case of a spherical contact; $C=6 /\left[\pi\left(1-v^{2}\right) \tan \beta\right]$, and $H=\delta^{2}$ for a conical contact.

For a linear viscoelastic model, the time-dependent generalization of Eq. Error! Reference source not found. is given by (16):

$$
\left.H(t)=\frac{1}{C} \int_{0}^{t} J\left(t-t^{\prime}\right) \frac{\mathrm{d} F\left(t^{\prime}\right)}{d t^{\prime}}=\frac{1}{C}\left[J(0) F(t)+\int_{0}^{t} \cdot \quad t^{\prime}\right) d t^{\prime}\right]
$$

where $J(t)$ is the dynamic compliance of the system that is to say, the deformation of the material at time $t: \chi(t)$ resulting from the application of a unit step of stress, $\sigma(0)$, at time $t=0$ :

$$
\gamma(t)=J(t) \sigma(0)
$$

For a Zener model representing a viscoelastic solid, we have:

$$
J(t)=\frac{1}{G_{0}}\left(1-\frac{G_{1}}{G_{1}+G_{0}} e^{-t / \tau}\right)
$$

with

$$
\tau=\tau_{1}\left(\frac{G_{1}+G_{0}}{G_{1}}\right) \text { and } \tau_{1}=\frac{\eta_{1}}{G_{1}}
$$

$\eta_{1}$ and $G_{1}$ are respectively the shear modulus and the viscosity of one branch of the model and $G_{0}$ is the shear modulus of the second branch, placed in parallel with the first one, $\tau$ the characteristic/relaxation time.

With the help of Eqs. Error! Reference source not found. and Error! Reference source not found. we are able to predict the indentation $\delta(t)$ for a given applied force $F(t)$. In order to check the validity of Eqs. Error! Reference source not found., Error! Reference source not found., we have compared the prediction of this model of dynamic indentation to the numerical results, which can be obtained by Finite Elements Method (FEM). We did this test for a spherical indenter using the software Abaqus, which can integrate the Zener model for the rheology of the material. The force $F(t)$ applied to the spherical particle in FEM and appearing in Eq. Error! Reference source not found. corresponds to a linear ramp reaching the value $C_{l}$ in $0.1 \mathrm{~s}$ and then obeying Eq. (6). The resulting indentation obtained either with the FEM software or with Eq. Error! Reference source not found. perfectly coincide (cf. Error! Not a valid bookmark self-reference.: Comparison between a linear viscoelastic model and FEM results for a Zener model with the parameters $\mathrm{G}_{0}=210 \mathrm{~Pa}, \mathrm{G}_{1}=118 \mathrm{~Pa}, \mathrm{~T}_{1}=5.6 \mathrm{~s}$ and the same applied sinusoidal force

), which validates the use of Eq. Error! Reference source not found. to predict the indentation depth for any kind of applied force. 


\section{FIGURES}

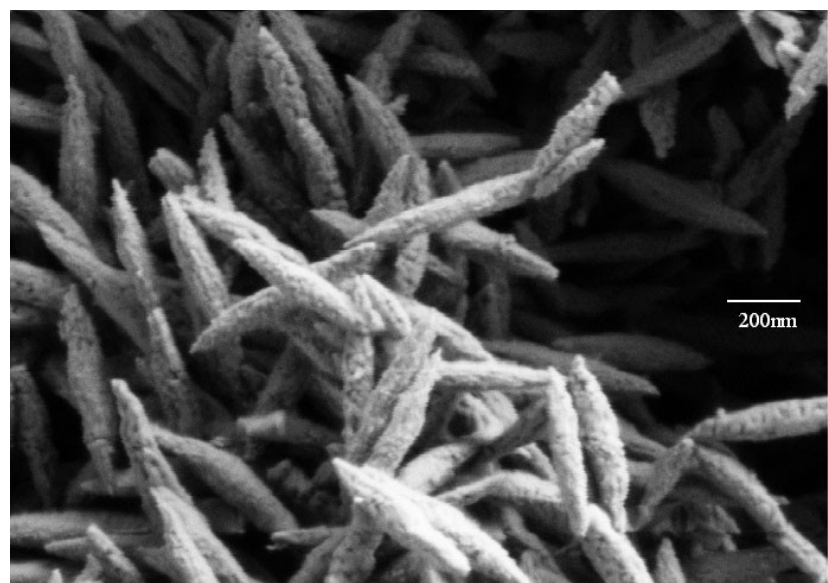

Error! Not a valid bookmark self-reference.: The SEM image of spindle like iron particles; upper picture: dimensions of a single particle; lower picture: particles covered with silica 


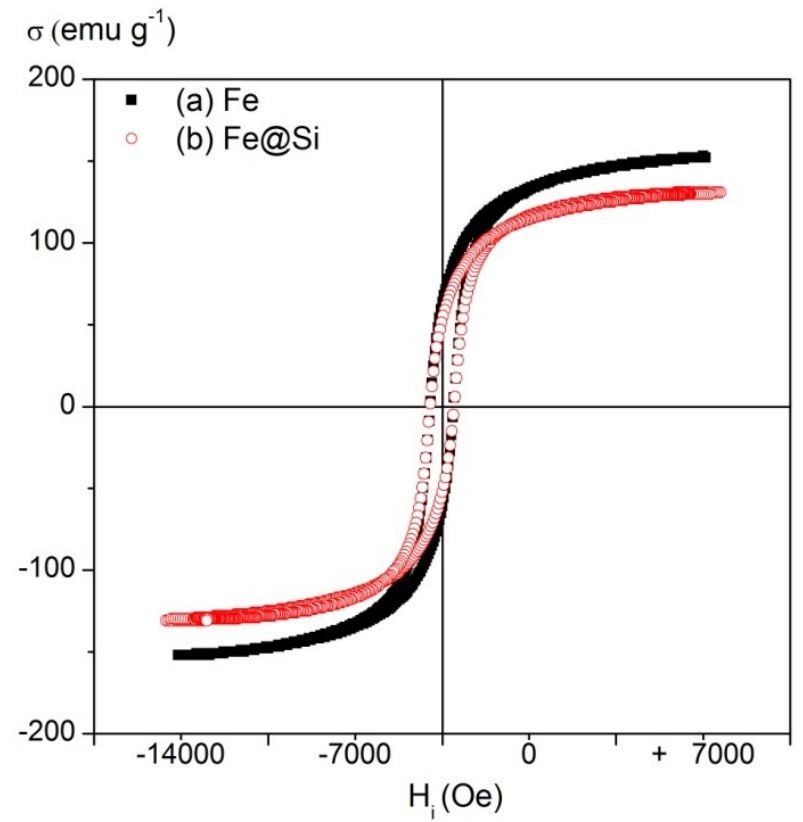

Error! Not a valid bookmark self-reference.: The magnetization curve of Fe (black) and Fe@Silica (red) spindle like particles 


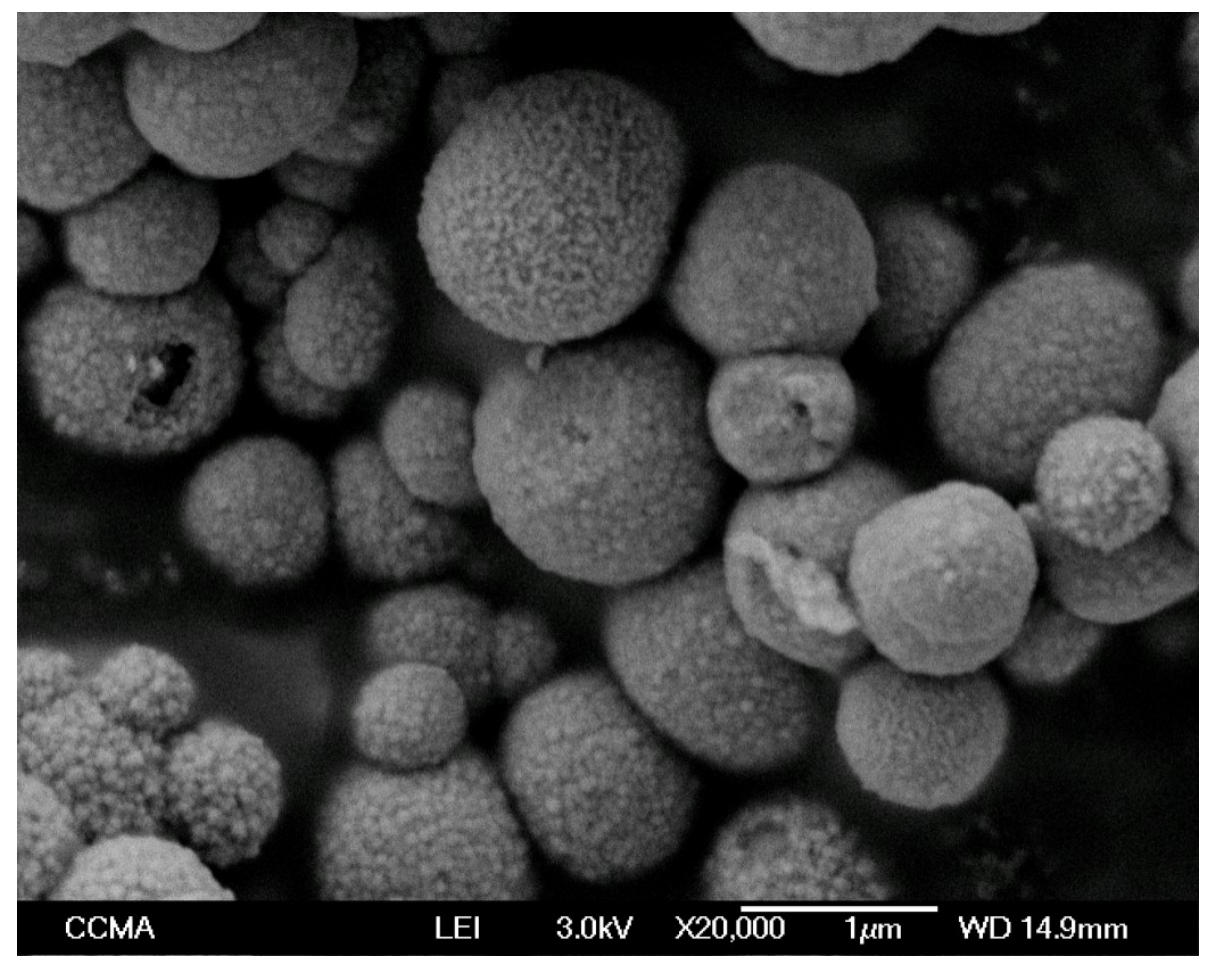

Error! Reference source not found.: The SEM image of BASF iron microparticles covered with APTES

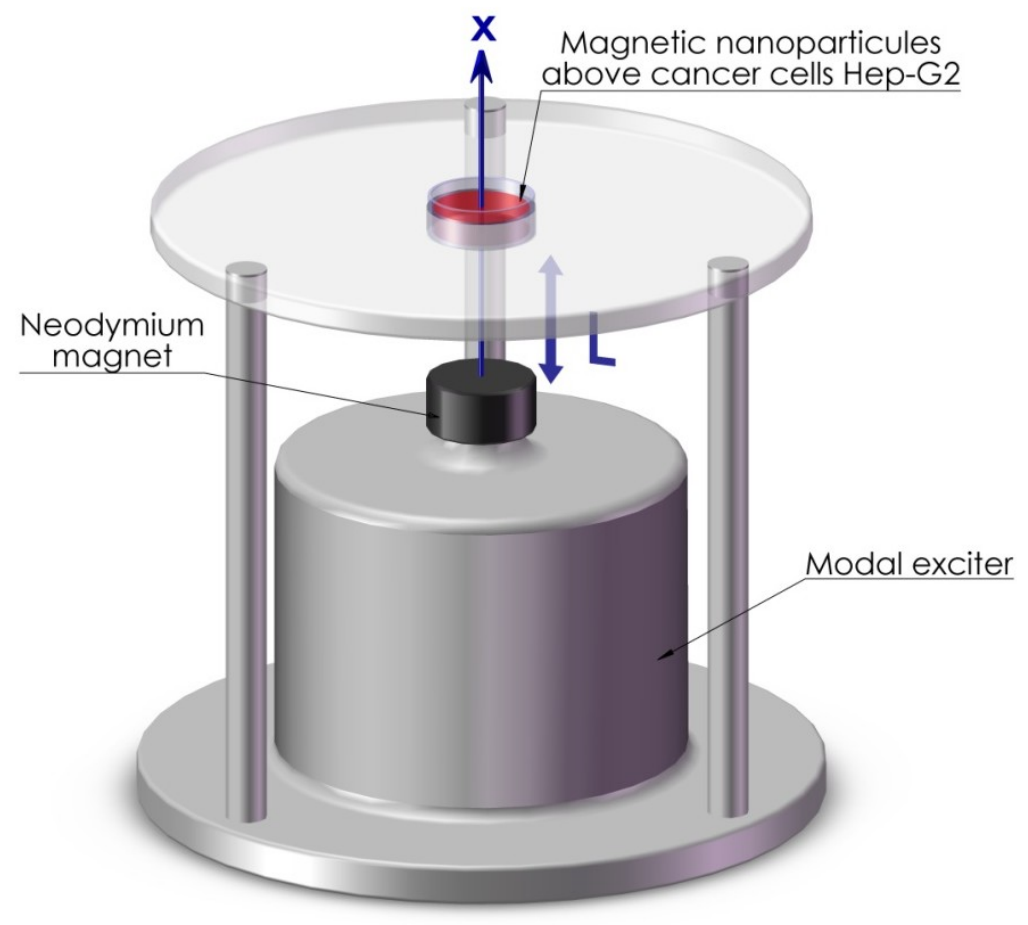

Error! Not a valid bookmark self-reference.: Experimental magnetolysis setup 


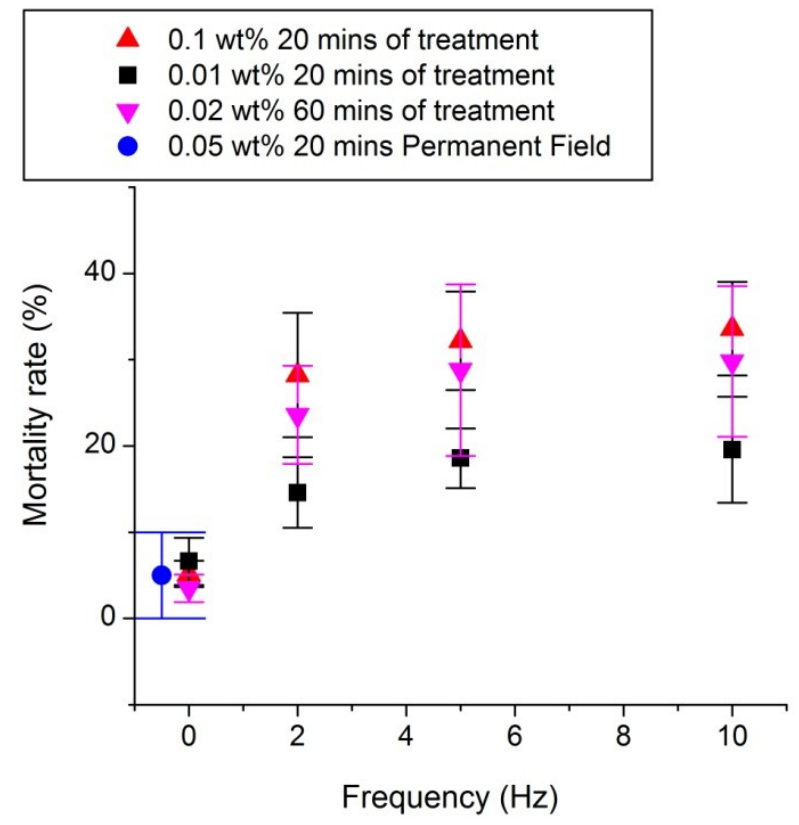

Error! Not a valid bookmark self-reference.: Mortality ratio for the spindle-type particles versus frequency of the magnetic field. The data at $0 \mathrm{~Hz}$ are without field, except the blue square, which corresponds to a permanent field $\mathrm{H}=160 \mathrm{kA} / \mathrm{m}$ 


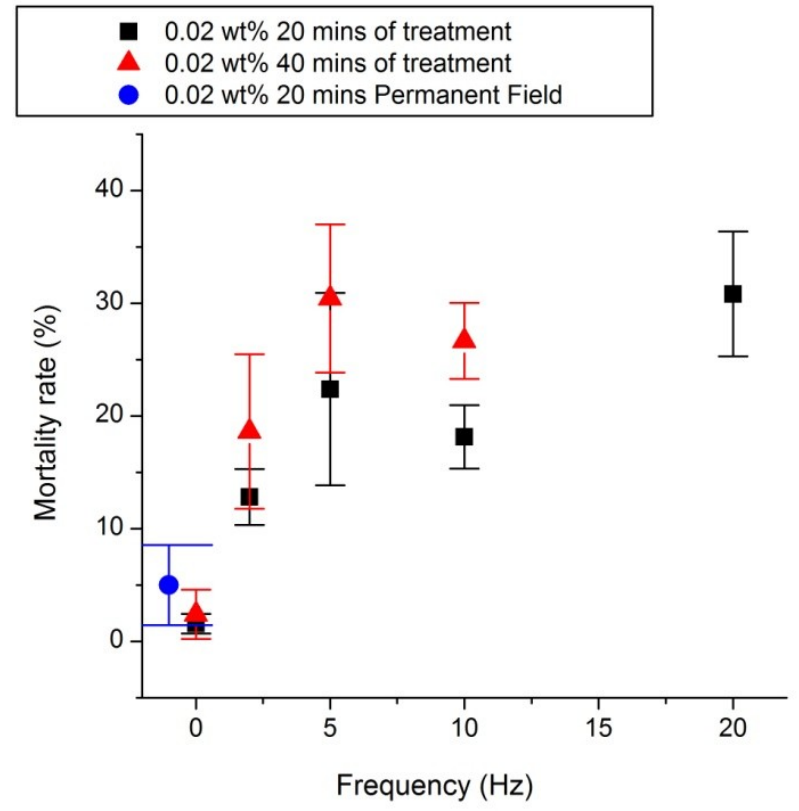

Error! Not a valid bookmark self-reference.: Mortality ratio for the spherical particles versus frequency of the magnetic field. The data at $0 \mathrm{~Hz}$ are without field, except the blue square, which correspond to a permanent field $\mathrm{H}=160 \mathrm{kA} / \mathrm{m}$ 


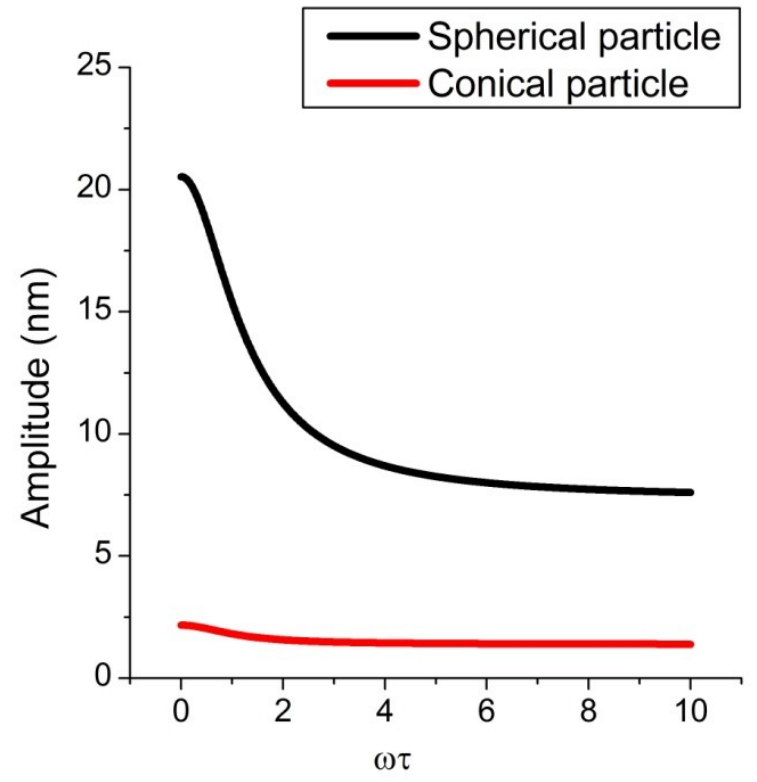

Error! Not a valid bookmark self-reference.: Amplitude of the oscillation versus the reduced frequency $\omega$ T. Upper and lower curves correspond to spherical and spindle like particles, respectively. 


\section{Before tapping}

\section{Target cell}

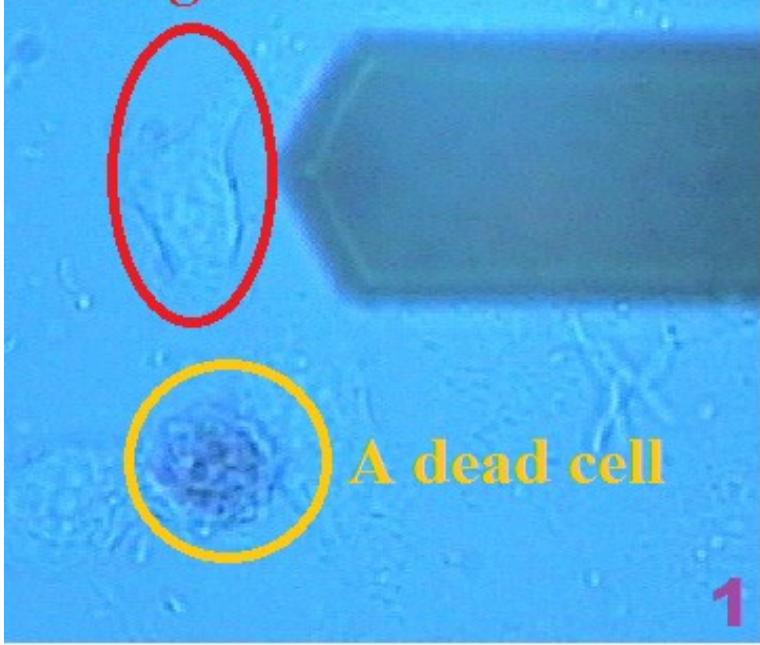

\section{5 min after tapping}

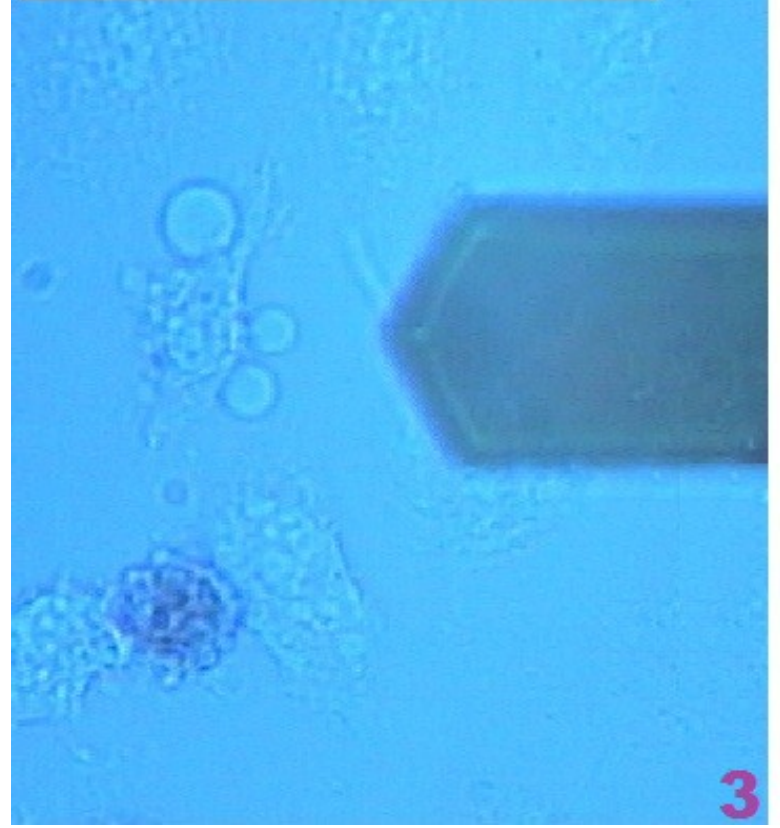

\section{End of tapping (20 $\mathrm{min})$}

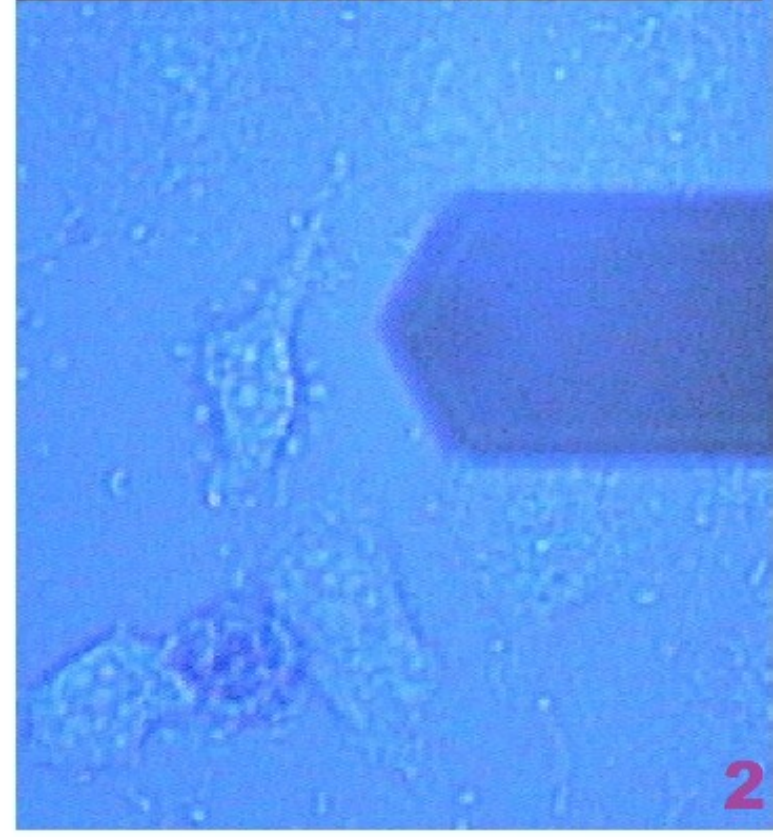

\section{1h after tapping}

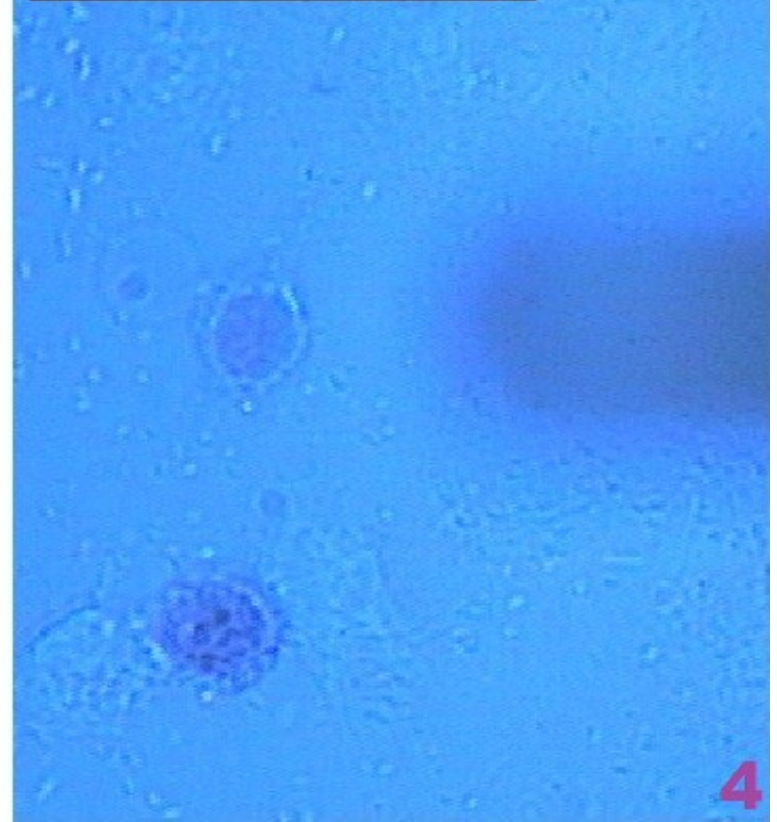

Error! Not a valid bookmark self-reference.: Mortality test of a $\mathrm{HepG}_{2}$ cell (red circle) by indentation with a conical AFM tip. (1) before treatment; (2) immediatly after indentation during 20 min; (3) 15 min and (4) $1 \mathrm{~h}$ after indentation.. The dead cell (yellow circle) is a landmark 

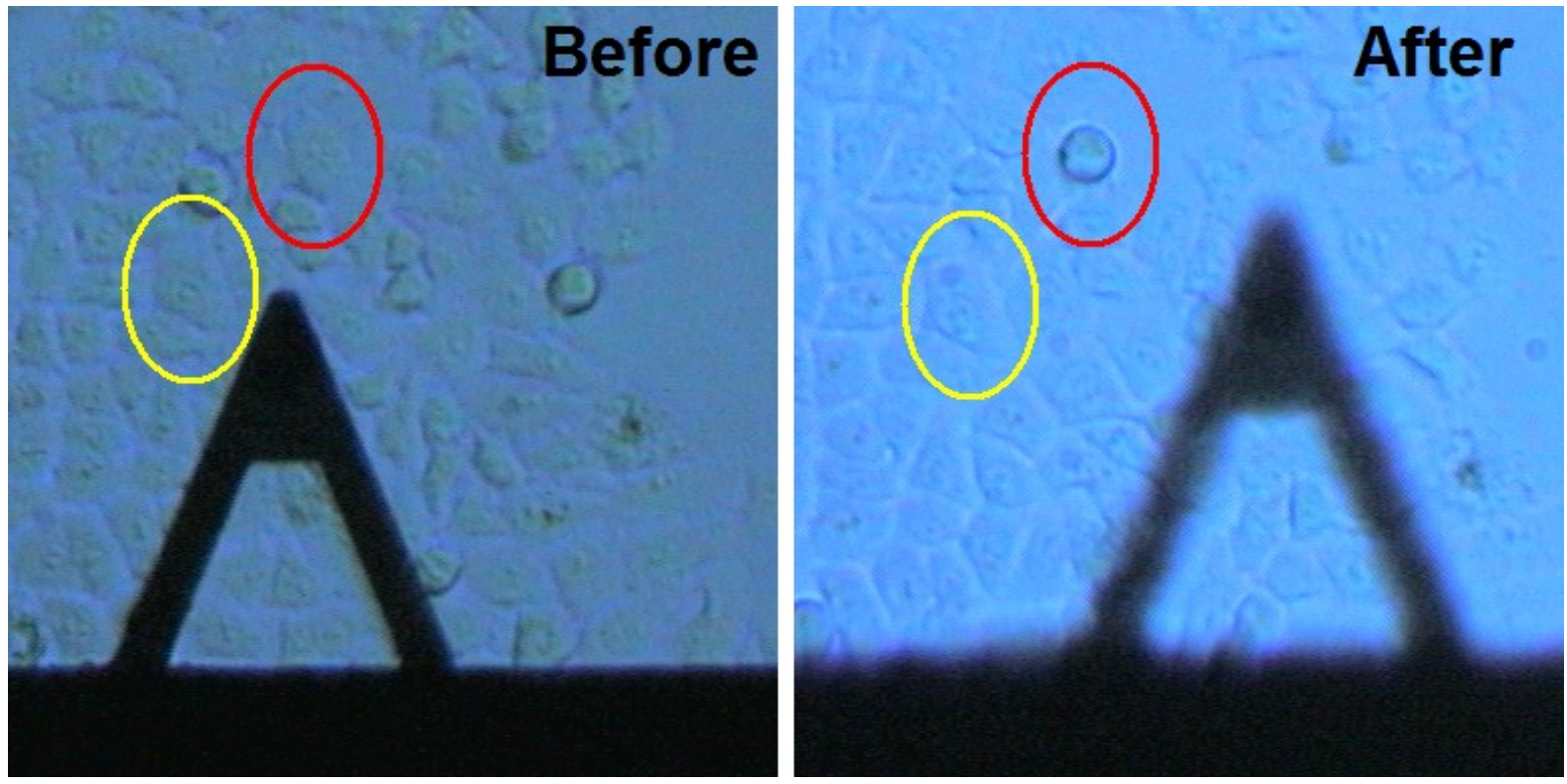

Error! Not a valid bookmark self-reference.: Mortality test of a $\mathrm{HepG}_{2}$ cell (red circle) by indentation with a spherical tip. left and right : before and after treatment for 20 min and with a frequency of $5 \mathrm{~Hz}$, respectively. Red and yellow circle: cell treated with an amplitude of 400 and $300 \mathrm{~nm}$, respectively. Red and yellow circle: cell treated with an amplitude of 400 and $300 \mathrm{~nm}$, respectively. 


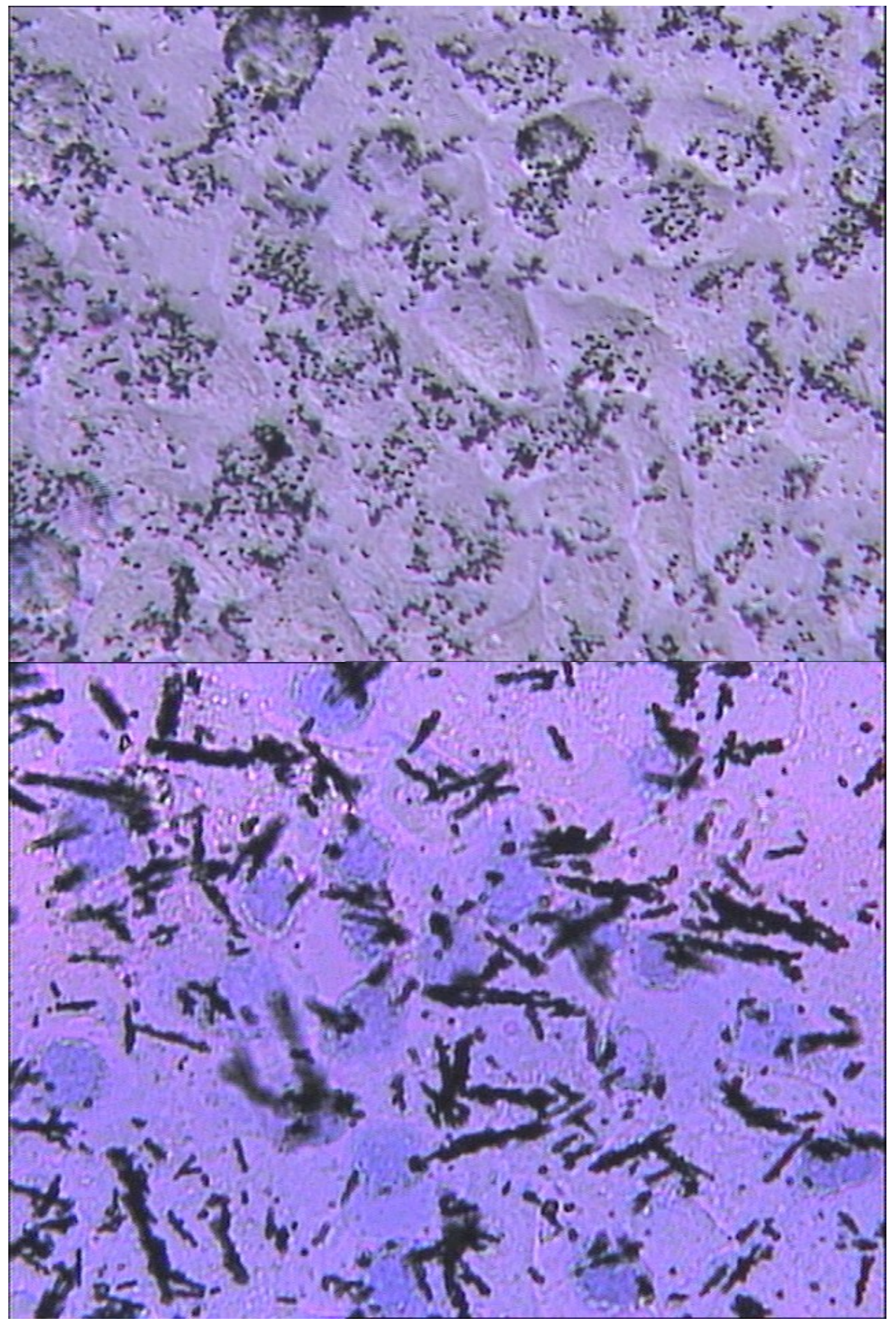

Error! Not a valid bookmark self-reference.: Photo of spherical iron particles above $\mathrm{HepG}_{2}$ cells before (upper part) and after (lower part) the application of the oscillating field. Average cell diameter is 25 $\mu \mathrm{m}$. The blue staining indicates dead cells 


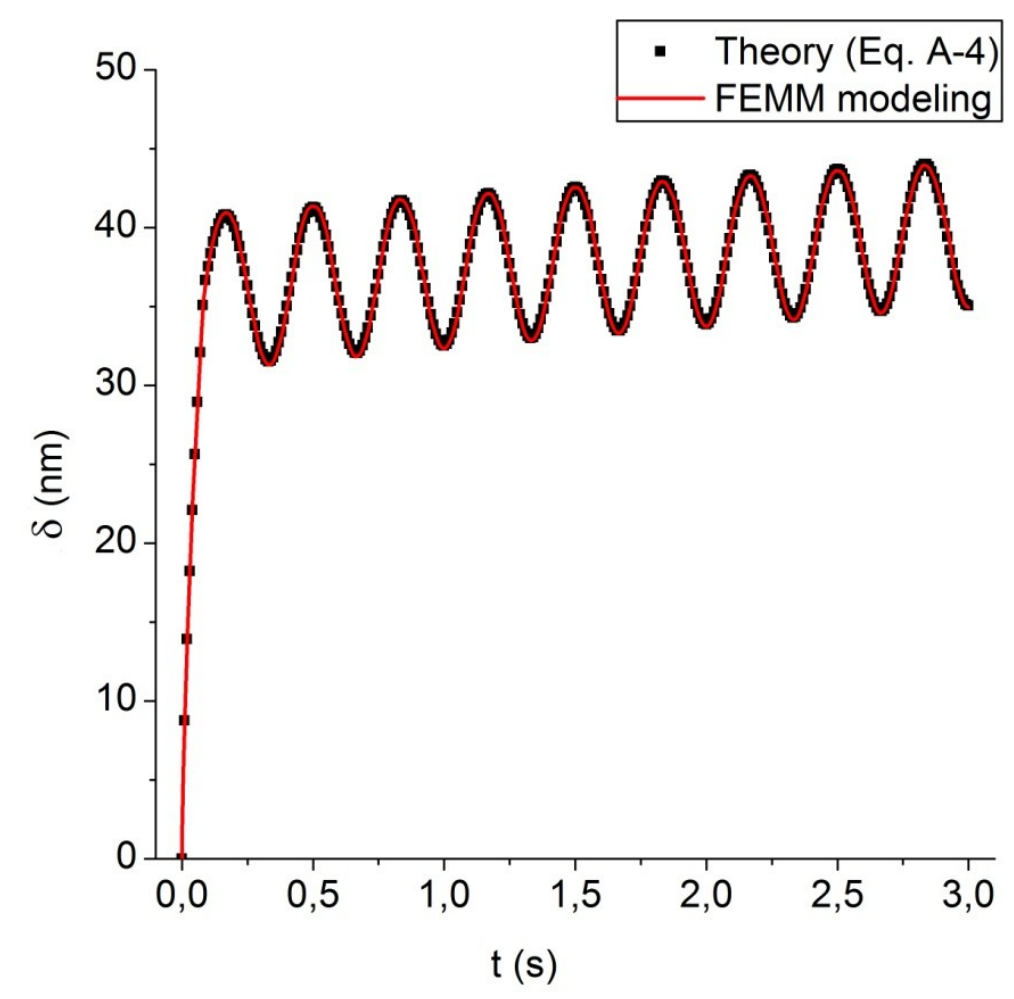

Error! Not a valid bookmark self-reference.: Comparison between a linear viscoelastic model and FEM results for a Zener model with the parameters $\mathrm{G}_{0}=210 \mathrm{~Pa}, \mathrm{G}_{1}=118 \mathrm{~Pa}, \mathrm{~T}_{1}=5.6 \mathrm{~s}$ and the same applied sinusoidal force 